\title{
sñoyulz
}

\section{Importância do monitoramento de processo e da melhoria continua no cumprimento do tempo porta- balão em até 90 minutos no protocolo de dor torácica}

\author{
Autores: Carolina F.Vasco, Vitor Alves Loures, Priscila Pereira Duarte de Oliveira, Suellen da Fonseca, \\ Humberto Cunha Castro \\ Intituição: Rede D'OR São Luiz Anália Franco
}

\section{Introdução:}

As doenças cardiovasculares constituem a principal causa de mortalidade e complicações intra-hospitalares no Brasil e Estados Unidos da América (EUA). Apenas no Brasil, entre 2001 e 2010, foram registrados mais de 1 milhão de óbitos por doenças do aparelho circulatório, sendo que os óbitos por infarto agudo do miocárdio (IAM) representaram $40,5 \%$ do total, com 603.932 óbitos.

\section{Objetivo:}

Garantir através da melhoria continua dos processos multidisciplinares envolvidos no protocolo de dor torácica o cumprimento do tempo porta balão em até 90 minutos

\section{Resultados:}

Através da atualização do protocolo de dor torácica, treinamentos da equipe da administração, tracer do paciente cardiológico no pronto socorro, sala e colaborador da enfermagem dedicado para a realização de ECG, ramal exclusivo para o acionamento da equipe de hemodinâmica, backup da equipe de enfermagem pela UTI cardiológica conquistamos um atendimento ágil e de qualidade aos pacientes com IAM com supra de ST

\section{Conclusão:}

No tratamento do IAMCSST há um indicativo de melhores desfechos quando o paciente procura atendimento com até 12 horas de sintomas e consegue ser atendido com tempo porta ECG de até 10 minutos, tempo portabalão inferior a 90 minutos. Mesmo sabendo que a trombólise é o tratamento mais disponível em relação à angioplastia primária, muitos estudos já comprovaram que a segunda é mais vantajosa em relação à primeira, por resultar em desfechos mais positivos para o paciente a curto e longo prazo, e também pelo fato de a trombólise possuir critérios mais rigorosos para ser realizada, devido ao risco de sangramento cerebral. Desta forma, torna-se indispensável o monitoramento deste processo e ações de melhoria contínua que contribuam para um desfecho favorável.

\section{Referências Bibliográficas:}

1) Pinto LLN, Correia AR, Donoso MTV, Matos SS, Manzo BF. Estratégias para reduzir o tempo porta-balão nos pacientes com infarto agudo do miocárdio. REME rev.min.enferm, 20, 2016;

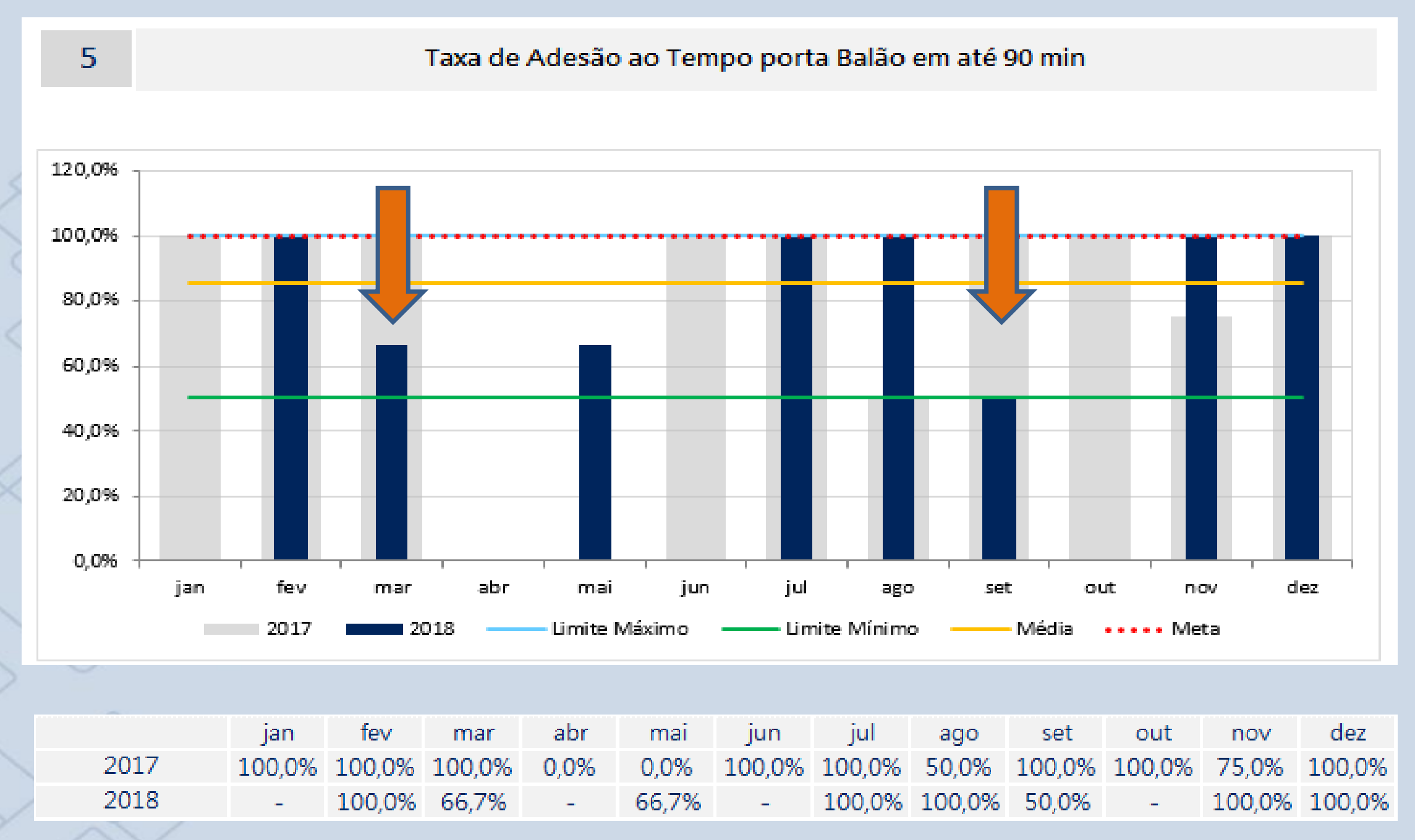

